\title{
Waste Heat Reutilization of Calcined Petroleum Coke
}

Dpen Access

\author{
Bin Zheng ${ }^{1, *}$, Yongqi Liu ${ }^{1, *}$, Ruixiang Liu ${ }^{1}$, Zuofeng Wang ${ }^{2}$, Zuoren Wang $^{2}$ and Xiaoni Qi ${ }^{1}$ \\ ${ }^{I}$ School of Transportation and Vehicle Engineering, Shandong University of Technology, Zibo 255049, China; \\ ${ }^{2}$ Weifang Lianxing New Material Technology Co., Ltd., Weifang 262737, China
}

\begin{abstract}
The waste heat reutilization system of calcined petroleum coke (CPC), installed in the tank calcined furnace, was built. The waste heat reutilization exchanger, included outer heat exchanger and inner heat exchanger, was designed. The axial fins be equipped with heat exchanger tube. The reutilization ratio of waste heat and temperature distribution of CPC were studied. The results showed that the waste heat of CPC is utilized by waste heat reutilization exchanger. The average reutilization ratio of waste heat is $78.9 \%$. Temperature of CPC decrease from heat exchanger inlet to outlet. In the horizontal plane, the maximum temperature point is the middle of space between inner heat exchanger and outer heat exchanger. In the heat exchanger outlet, the temperature of CPC is low. The nonuniformity coefficient value of temperature is 0.0757 . The uniformity degree of temperature is better. The oxidation combustion reaction could be prevented.
\end{abstract}

Keywords: Calcined petroleum coke, fin-and-tube, heat exchanger, reutilization, waste heat.

\section{INTRODUCTION}

$\mathrm{CPC}$ is one of the important basic raw materials. It is widely used in producing anode of aluminum electrolytic, graphite electrode, recarburizer, industrial silicon and other carbon products. The China's production capacity of CPC is largest in the world, above $70 \%$ of which is produced in tank calcined furnaces. The high temperature flue gas waste heat and high temperature CPC waste heat could be utilized in calcination process of petroleum coke. The reutilization technology of the high temperature flue gas waste heat has been used widely [1-3]. When CPC discharged from tank calcined furnaces, the temperature is $1000{ }^{\circ} \mathrm{C}$. The waste heat of it has high potential to be utilized.

Waste heat reutilization of the solid material had been studied in some field. The waste heat of the high temperature steel slag be utilized by rotary cylinder atomizing method and air nozzle method [4, 5]. Liu [6] studied heat transfer characteristics of apparatus for recycling the waste heat of blast furnace slag. The factors, which influence the heat transfer coefficient, the cooling rate of slag particle around the first row of tubes and the heat recovery, are slag particle diameter, slag particle speed, the arrangement of tubes, the Reynolds number of water and the flow patterns of water. Yang [7] studied the coupling characteristics of granular medium flow and heat transfer parameters. Different character particles were tested and analyzed, including compound fertilizer of three particle sizes, zeolite of two particle sizes and aluminum fluoride. Di [8] introduced microscopic models of the fluid-particle, particle-particle, fluid-surface and particle-surface heat transfer using DEM-CFD hydrodynamic code. Takouch [9] studied flow visualization of flowing particles around a tube of various types of tube

\footnotetext{
*Address correspondence to these authors at the School of Transportation and Vehicle Engineering, Shandong University of Technology, Zibo 255049, China; Tel: +86-533-2782616; Fax: +86-533-2782616;

E-mails: liuyq65@163.com and sdutzb@163.com
}

arrangements in a moving bed using X-ray video films to obtain a relation between particles behavior and local heattransfer coefficients. Wu [10] simulated heat transfer between particles and inserted heating surface by the model combined with discrete element methods (DEM).

The investigations on the reutilization technology of CPC waste heat are lacked. In this paper, waste heat reutilization of CPC were studied by the waste heat reutilization system.

\section{EXPERIMENTS}

The waste heat reutilization system of CPC was built in Weifang Lianxing New Material Technology Co. Ltd. (Fig. 1). The waste heat reutilization experiments were carried out. The system is composed of waste heat reutilization exchanger, CPC supply system, water circulation system and measurement system.

(1) Waste heat reutilization exchanger: The heat exchanger includes outer heat exchanger and inner heat exchanger. The axial fin be equipped with heat exchanger tube. Its structure be shown in Fig. (2).

(2) CPC supply system: The system is installed in the tank calcined furnace. The high temperature CPC is directly supplied from tank calcined furnace.

(3) Water circulation system: This system is composed of cooling pond, pumps, valves, sight glass, drum and so on. There is a FLUXUS F601 ultrasonic flowmeter in the heat exchanger inlet, which is used for measuring the water flow. Its measuring accuracy is $\pm 0.5 \%$. Its repeatability is $0.15 \%$. Its measuring velocity range is from $0.01 \mathrm{~m} / \mathrm{s}$ to $25 \mathrm{~m} / \mathrm{s}$. There is a WSM-D two-phases flowmeter in the heat exchanger outlet, which is used for measuring steam dryness and flow.

(4) Measurement system: This system is composed of temperature sensor, pressure sensor and data acquisition 


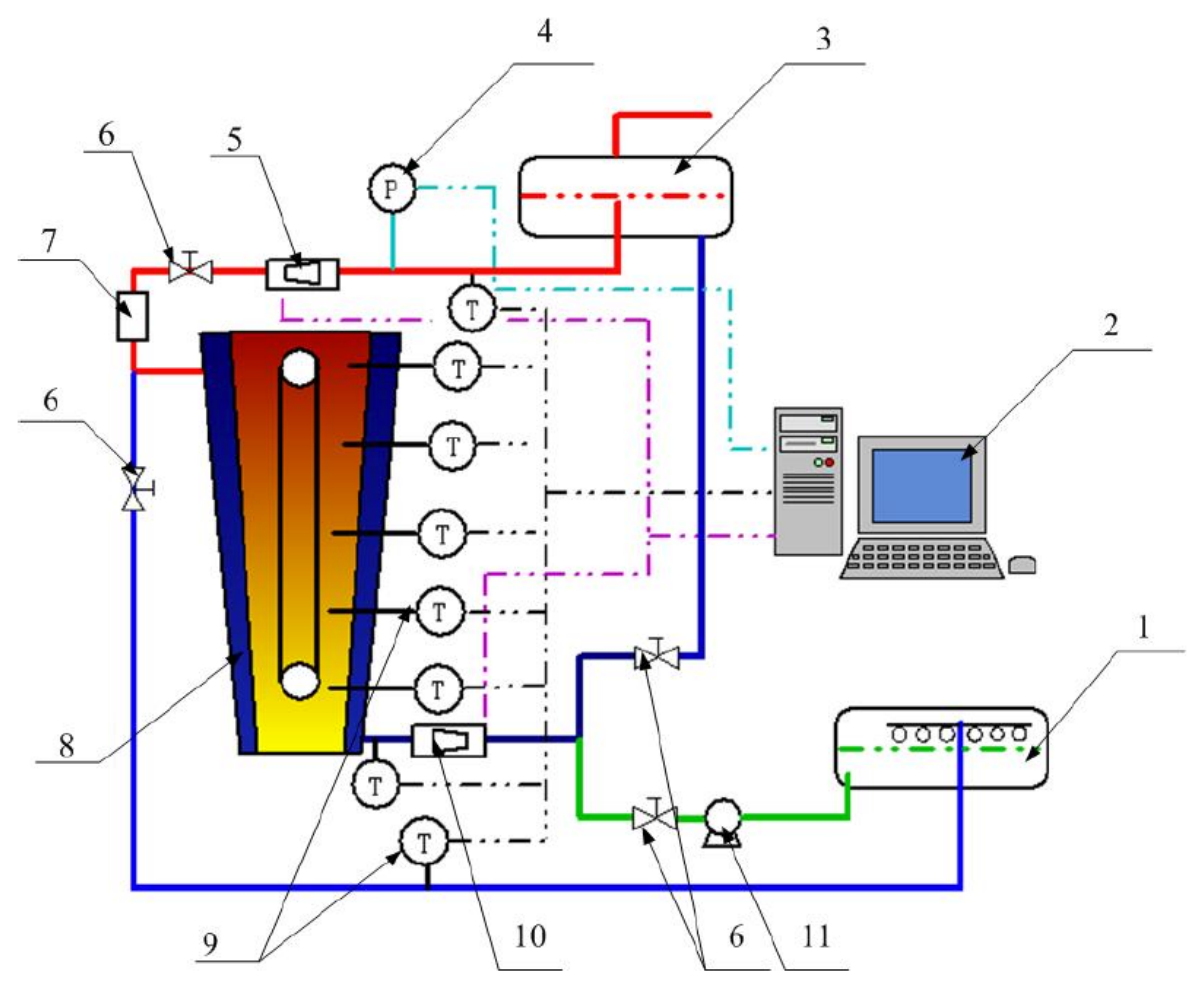

Fig. (1). Schematic of waste heat reutilization system (1. cooling pond; 2. data acquisition system; 3. drum; 4. pressure sensor; 5. two-phases flowmeter; 6. valve; 7. sight glass; 8. fin-and-tube waste heat exchanger; 9. temperature sensor; 10. flowmeter; 11. pump).

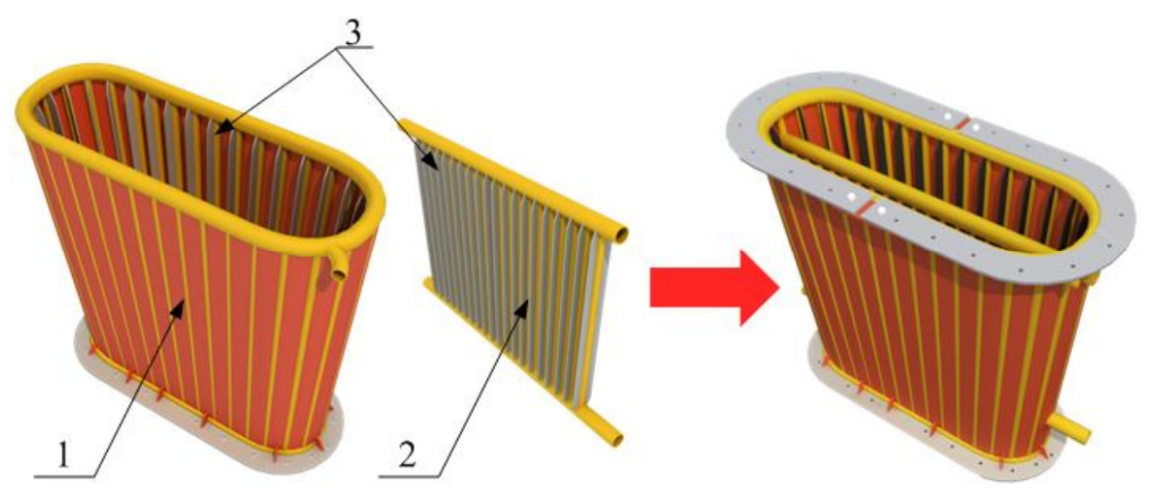

Fig. (2). Schematic of waste heat reutilization exchanger (1. outer heat exchanger; 2. inner heat exchanger; 3. fin).

instrument. Temperature sensor is used for measuring the temperature of CPC in heat exchanger, the temperature of water in the heat exchanger inlet, the temperature of steam in the heat exchanger outlet and so on. Pressure sensor is used for measuring the steam pressure and the water pressure. The data acquisition instrument is used for recording data. The temperature measuring points of $\mathrm{CPC}$ in heat exchanger be shown in Fig. (3).

The reutilization ratio of waste heat is calculated by the equation (1):

$$
\eta=\frac{q_{1} \cdot\left(h_{\text {out }}-h_{i n}\right)}{c \cdot q_{2} \cdot T} \times 100 \%
$$

Where $\eta$ is reutilization ratio of waste heat, $\% ; q_{l}$ is water flow, $\mathrm{kg} \cdot \mathrm{h}^{-1} ; h_{\text {out }}$ is enthalpy value of heat transfer medium in the heat exchanger outlet, $\mathrm{kJ} \cdot \mathrm{kg}^{-1} ; h_{i n}$ is enthalpy value of water in the heat exchanger inlet, $\mathrm{kJ} \cdot \mathrm{kg}^{-1} ; c$ is specific heat capacity, $\mathrm{kJ} \cdot \mathrm{kg}{ }^{-1} \cdot{ }^{\circ} \mathrm{C}^{-1} ; q_{2}$ is $\mathrm{CPC}$ flow, $\mathrm{kg} \cdot \mathrm{h}^{-1} ; T$ is temperature of $\mathrm{CPC}$ when it gets into the heat exchanger, ${ }^{\circ} \mathrm{C}$.

The nonuniformity coefficient of temperature is calculated by the equation (2):

$$
\gamma=\frac{\Delta T_{\max }}{T_{\text {ave }}}
$$

Where $\gamma$ is nonuniformity coefficient of temperature; $T_{\text {ave }}$ is average temperature value of CPC in the horizontal plane, ${ }^{\circ} \mathrm{C} ; \triangle T_{\max }$ is maximum temperature difference value of CPC in the horizontal plane, ${ }^{\circ} \mathrm{C}$.

\section{RESULTS AND DISCUSSIONS}

The temperature rules of CPC in the inlet and outlet of the waste heat reutilization exchanger during 24 hours are shown in Fig. (4). The temperature fluctuation of CPC in the heat exchanger inlet be influenced by calcined furnace 


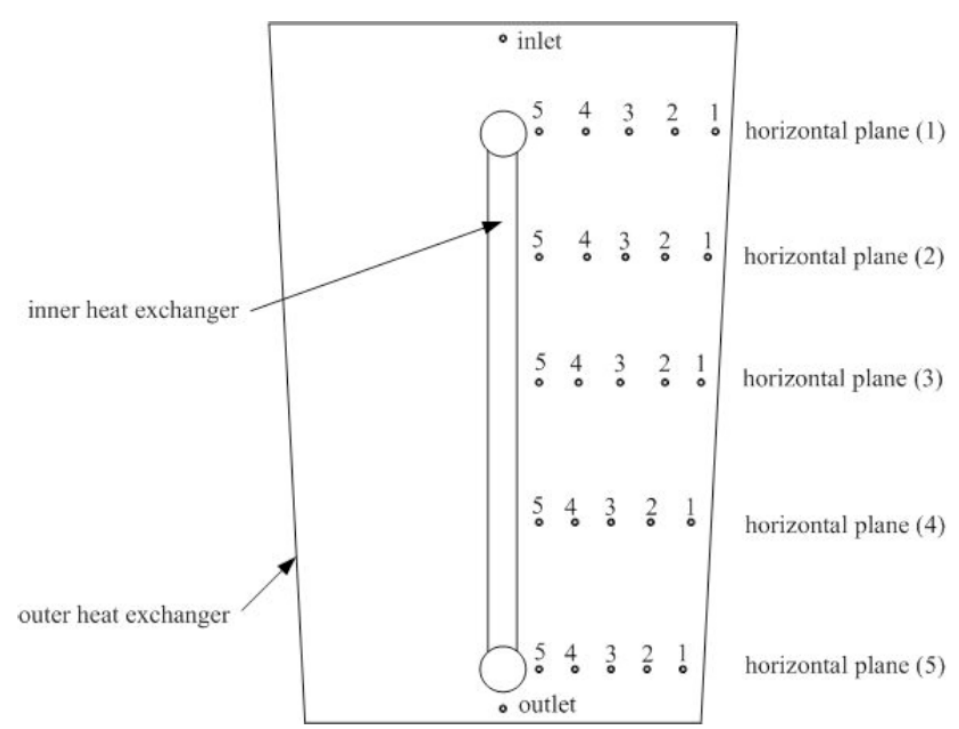

Fig. (3). The temperature measuring points of $\mathrm{CPC}$ in waste heat exchanger.

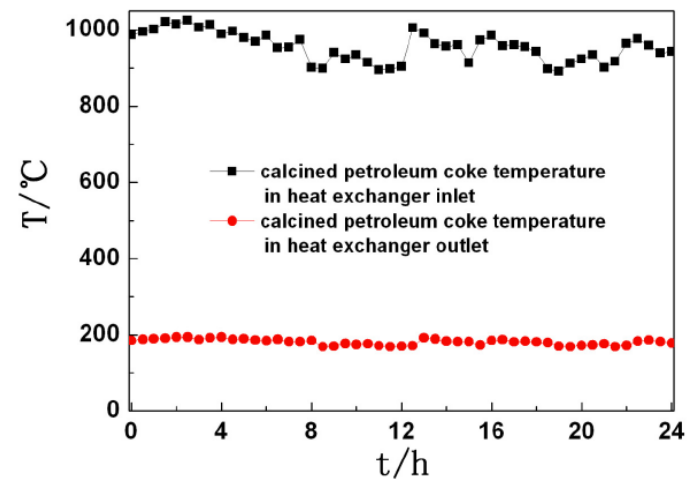

Fig. (4). The temperature rules of CPC which in the inlet and outlet of the waste heat exchanger.

operation fluctuation. But the temperature fluctuation range is small. The average temperature of $\mathrm{CPC}$ is $958{ }^{\circ} \mathrm{C}$ in the heat exchanger inlet. In the heat exchanger outlet, the temperature of $\mathrm{CPC}$ is low. The temperature fluctuation range of $\mathrm{CPC}$ is small. The average temperature of $\mathrm{CPC}$ is only $181^{\circ} \mathrm{C}$.

The steam producing rate of waste heat reutilization exchanger and reutilization ratio of waste heat during 24 hours are shown in Fig. (5). They are stable, and the fluctuation range is small. The steam phase is saturated steam, where saturation pressure is $1.0 \mathrm{MPa}$. The average steam producing rate of waste heat exchanger is $75.6 \mathrm{~kg} / \mathrm{h}$. The average reutilization ratio of waste heat is $78.9 \%$.

The temperature distributions of $\mathrm{CPC}$ in heat exchanger are shown in Fig. (6). Temperature of CPC decreases from heat exchanger inlet to outlet. In the horizontal plane, the maximum temperature point is the middle of space between inner heat exchanger and outer heat exchanger. Temperatures on both sides of CPC decrease gradually. In the first horizontal plane, the maximum temperature is $863{ }^{\circ} \mathrm{C}$, but the minimum temperature is $405^{\circ} \mathrm{C}$. The temperature difference is $458{ }^{\circ} \mathrm{C}$. The nonuniformity coefficient value of temperature is 0.411 . The uniformity degree of temperature is low. The reason is that the heat conductivity coefficient of

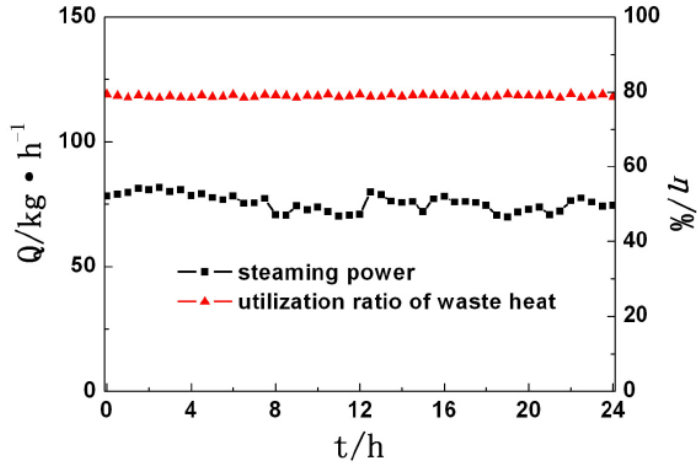

Fig. (5). The steam producing rate of waste heat exchanger and reutilization ratio of waste heat.

CPC is small, which leads to the great temperature gradient. With CPC moves to the heat exchanger outlet, The nonuniformity coefficient of temperature increase gradually. In the fifth horizontal plane, the maximal temperature is $249^{\circ} \mathrm{C}$, but the minimum temperature is $215^{\circ} \mathrm{C}$. The temperature difference is $34{ }^{\circ} \mathrm{C}$. The nonuniformity coefficient value of temperature is 0.0757 . The uniformity degree of temperature is better than that of the first horizontal plane.

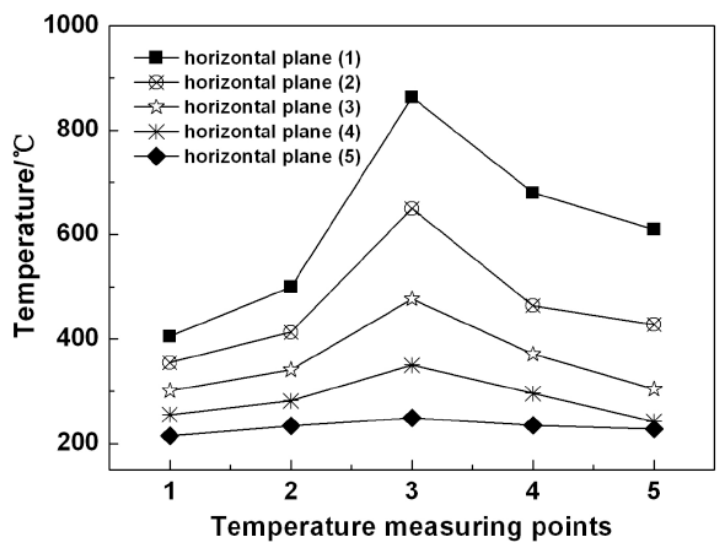

Fig. (6). The temperature distributions of CPC in heat exchanger. 
To sum up, the waste heat of CPC is utilized by waste heat reutilization exchanger. The saturated steam is gained. In the heat exchanger outlet, the temperature of CPC is low. The uniformity degree of temperature is better. The oxidation combustion reaction could be prevented.

\section{CONCLUSION}

The waste heat of CPC is utilized by waste heat reutilization exchanger. The average steam producing rate of waste heat exchanger is $75.6 \mathrm{~kg} / \mathrm{h}$. The average reutilization ratio of waste heat is $78.9 \%$. Temperature of CPC decreases from heat exchanger inlet to outlet. In the horizontal plane, the maximal temperature point is the middle of space between inner heat exchanger and outer heat exchanger. Temperatures on both sides of CPC decrease gradually. In the heat exchanger outlet, the temperature of $\mathrm{CPC}$ is low. The uniformity degree of temperature is better. The oxidation combustion reaction could be prevented.

\section{CONFLICT OF INTEREST}

The authors confirm that this article content has no conflicts of interest.

\section{ACKNOWLEDGEMENTS}

This work was financially supported by Shandong Provincial Natural Science Foundation, China (No. ZR2013EEQ005), Shandong Provincial Science and Technology Development Program, China (No. 2013GGX10404) and Weifang Science and Technology Development Program (No. 20121148).

\section{REFERENCES}

[1] P. Wang, and Y. Luo, "Developing characteristics and technical advancement of carbon anode industry in China in recent years," Carbon Techniques, vol. 30, pp. 40-46, 2011.

[2] H. Vendette, and B. Cloutier, "Anode paste plants: innovative solution for optimum emission performances," In: J. A. Johnson (Ed.), Proceedings of the 2010 TMS Annual Meeting \& Exhibition, Seattle, WA , pp. 993-996, 2010.

[3] Y. Sun, "Analysis on the energy conservation and emission reduction technology in Chinese carbon industry," Carbon Techniques, vol. 31, pp. 1-5, 2012.

[4] L. Rodd, T. Koehler, and C. Walker, "Economics of slag heat recovery from ferronickel slags: sustainability for profit," In: G. Richards (Ed.), Proceedings of the 49th Annual Conference of Metallurgists, Vancouver, pp. 3-17, 2010.

[5] Y. Kashiwaya, Y. In-Nami, and T. Akiyama, "Development of a rotary cylinder atomizing method of slag for the production of amorphous slag particles," ISIJ International, vol. 50, pp. 12451251, 2010.

[6] J. Liu, "Experimental study on heat transfer characteristics of apparatus for recycling the waste heat of blast furnace slag", M.S. thesis, Northeastern University, Shenyang, Liangning, China, 2009.

[7] L. Yang, "Research of the coupling characteristics of granular medium flow and heat transfer parameters", M.S. thesis, Dalian University of Technology, Dalian, Liangning, China, 2007.

[8] F. P. Di Maio, A. Di Renzo, and D. Trevisan, "Comparison of heat transfer models in DEM-CFD simulations of fluidied beds with an immersed probe," Powder Technology, vol. 193, pp. 257-265, 2009.

[9] H. Takeuchi, "Particles flow pattern around tube and local in moving heat transfer bed," AIChE Journal, vol. 42, pp. 1621-1626, 1996.

[10] J. Wu, J. Chen, and Y. Yang, "Model of contact heat transfer in granular moving bed," Journal of Chemical Industry and Engineering, vol. 57, pp. 719-725, 2006.

\begin{tabular}{lcc}
\hline Received: February 18, 2014 & Revised: March 11,2014 Accepted: March 11, 2014 \\
C) Zheng et al.; Licensee Bentham Open. & & A
\end{tabular}

This is an open access article licensed under the terms of the Creative Commons Attribution Non-Commercial License (http://creativecommons.org/licenses/by-nc/3.0/) which permits unrestricted, non-commercial use, distribution and reproduction in any medium, provided the work is properly cited. 